\title{
ADOLESCENTS' GENDER IDENTITY AND ATTITUDE TOWARDS PARENTS
}

\author{
Blandína Šramová \\ Tomas Bata University in Zlin (Czech Republic)
}

\begin{abstract}
The focus of the project is on the adolescents' perception of the roles of a mother and a father in the family, and specifically on adolescent boys' attitude towards their fathers and adolescent girls' attitude towards their mothers. There has been a noticeable shift in interests that used to be primarily associated with a certain gender. For instance, men are increasingly more concerned with the body image, which used to be a predominantly female domain. Moreover, the role of a father has been changing recently, to the point of so-called fatherhood crisis. The role of a father is built around strong social, cultural, and historical constructs of hegemonistic masculinity. Our research based on qualitative design (discourse method) uncovered attitudes of adolescent boys $(\mathrm{N}=25)$ towards their fathers, and attitudes of adolescent girls $(\mathrm{N}=26)$ towards their mothers. Adolescent boys were shown to have a more problematic relationship with their fathers, and a significantly positive relationship with their mothers. Mothers not only represent an essential part of their lives, but also provide an emotional and mental support. Adolescent girls identified more with their mothers, highlighting mothers' ability to handle a vast number and diversity of family matters. The key factor in the positive rating of a mother was represented by safe emotional ties between the mother and daughter. However, in cases where these ties were missing, mother was perceived through the lenses of stereotypically female depictions, largely perpetuated by the mass media and agendas of certain political parties. The present study is a part of the project VEGA 1/0191/19.
\end{abstract}

Keywords: Gender, identity, adolescents, stereotypes.

\section{Introduction}

"What is and what will be my place in society?" is an identity question strongly linked with the period of adolescence (Erikson, 1968). This period in life is characterised by the creation of foundations of person's individual and social identity. One part of identity is gender identity, which is a social and cultural construct that distinguishes between female and male characteristics. The development of gender identity in a child is largely influenced by their mother and father. Parents represent the most crucial social institutions helping the child with orientation in and identification with specific gender characteristics. The nature and quality of the relationship between a parent and a child determines the course of the psychosocial development of the child, and whether the child will or will not see themselves as a person worth of love (Laible, Carlo \& Roesch, 2004). The formation of gender identity is often influenced by the different attitudes of a mother towards her daughter and son - daughters are "trained" to continue on with the female role, whereas sons are given more freedom and independence (Hirsh, 1981). The presented paper focuses on gender roles and adolescents' attitudes towards their mother and father.

\section{Gender role}

Formation of role identity represents an important part of adolescence when questions such as "Who am I?", "What is my place in society?", "What is my future role as an adult?", roam around the young mind of an adolescent. In the process of formation of role identity, the following institutions play key roles: family, school, media, and peers. The presented paper focuses on the identity formation of girls and boys during the sensitive period of adolescence, with emphasis on the role of a father in relation to his son, and on the role of a mother in relation to her daughter.

The mother-daughter relationship is considered to be essential in the identity formation of an adolescent girl. A higher degree of control and critical attitude from the mother's side can lead to cracks in the mother-daughter relationship, especially when an explanation of this behaviour and open 
communication are missing. Every so often, the mother does not distinguish between her identity and her daughter's identity and projects her own identity onto her daughter (Poncet-Bonissol, 2015). The mother's attitude towards her child has a considerable influence on how the child perceives the world and provides the foundations to the child's ability to create interpersonal relationships. The nature of this mother-child relationship, the degree of acceptance and emotional ties, impacts the child's subsequent journey through life. Since the mother identifies more with her daughter, she sees her as her successor, as a way of continuing her legacy. Problems in the mother-daughter relationship may arise when the mother does not give the daughter enough space for personal development. According to S. Beauvoire (1968), the image of the woman the daughter is supposed to become originates from the mother. However, this image is complicated by the reality of the daughter's observation of the mother's interactions with her partner. The ideas about the world and the future are based on these observations, which, instead of leading to self-discovery and catering to own desires, results in behaving in a way that caters to men's ideals.

On the other hand, the case of masculinity is absent of clarity and instead full of controversy and confusion. Masculinity has always been characterised based on the standards of a specific historical period. Media often present male characters as decisive, competent, and having everything under control. Thus, women appreciate sensitive men who are not afraid of showing weakness, but at the same time, want men who are unyielding and refuse to bend to the circumstances. However, it is difficult for real men to adhere to both sides of these standards (Lindsey, 2016).

Recently, we are witnessing a change in the role of the father in the family. It is important to note, however, that the so-called norms of what is admissible, desired, and refused, in a society, depends not only on a specific period but also on a specific society. Looking at our society (i.e., $21^{\text {st }}$ century Europe), the role of a father is no longer so strongly linked with rationality, goal-orientation, and providing financial security for the family (Oláh, Kotowska \& Richter, 2018). In the current world where both of the parents are working full-time, it is necessary that the father is involved in the parental care, which transforms the typical hegemonistic model of masculinity into a new model of fatherhood (Miller, 2011). Societal pressure, as well as the father's need to take part in taking care of the children, does not manifest only in fathers taking parental leave (which used to be a domain of the mothers) but also in partaking in free-time activities with their children. Media usually depicts this "transformed" type of father as a of positive, self-confident, decisive, and responsible male model.

However, on the political level, a so-called fatherhood crisis is being increasingly discussed. The most discussed questions on the topic of the fatherhood crisis and the change in the family structure in general, are tied to the high number of divorces, parents living outside of the wedlock, single parents, and so on. Some authors point to the emergence of a new phenomenon, de-gendering of the parenting role (Silverstein et al., 2002), which is tied to a certain level of uncertainty in the gender roles in parenting, as well as to a decreasing value of the father's role in the upbringing of the children. This can result in fathers being unprepared for the fatherhood, and in the mounting tension between the father and the son. Similar to the aforementioned mother-daughter relationship and its impact on the daughter's female role formation, the father-son relationship also determines the son's identification with the male role and the future father role.

Therefore, our aim in this study was to discover the nature of the father-son and of the mother-daughter relationship, as well as how the adolescents perceive the roles of a mother and a father.

\section{Methods}

A qualitative discourse method was used to uncovered attitudes of adolescent boys $(\mathrm{N}=25)$ towards their fathers, and attitudes of adolescent girls $(\mathrm{N}=26)$ towards their mothers. Both groups were aged between 18 and 19 years old. A focus groups discussions ( $\mathrm{N}=5$ for girls, $\mathrm{N}=5$ for boys) with the same moderator were conducted (Krueger \& Casey, 2000). Each discussion lasted for about 2 hours, was recorded on audio tapes, and subsequently transcribed. During each focus group discussion, the moderator introduced the following core set of questions (note that boys were asked the first option and girls were asked the second option): "How do you perceive yourself in the role of a boy/girl?"; "What is your perception of fatherhood/motherhood?"; "What is your relationship with your father/mother?"; "What do you not like about your father/mother?"; "What do you admire in your father/mother?"; "What kind of a father/mother would you like to be?"; "What kind of a mother/father should your partner be?". The primary data sources were transcripts, together with field-notes and brief summaries taken during or immediately after the discussions. We interpreted the data as discursive utterances of individuals in a semi-public context. After that, we focused our attention on the thematic contents which are constituent parts of a constructed role identity. 


\section{Results}

The analysis was focused on identifying the key themes that define the role of a father (according to adolescent boys) and the role of a mother (according to adolescent girls).

The discourse method of role identity pointed to the 3 following areas: 1) physical appearance (for boys: attractive, groomed, good looking, strong; for girls: pretty, slim, good looking); 2) mental qualities (for boys: brave, wise; for girls: nice, kind, perceptive); 3) utilitarian needs (for both boys and girls: rich).

The question on how the adolescents perceive their mother (girls) or their father (boys), both groups adopted a rather critical stance. Both adolescent girls and boys expressed high level of criticism of their parents, and in certain cases even refusal. Statements like "my mum is constantly unsatisfied with me", "my mum only criticizes me" appeared in the girl group, however, more prevalent were statements uncovering acceptance and social support from the mothers' side ("my mum is my best friend", "I can tell my mum everything"). On the other hand, boys' critical statements about their fathers were more dominant ("my dad just swears", "we would fare better without him, he just yells all the time"). Adolescent boys confessed to having a better relationship with their mother who is considered to be an emotional and moral pillar of the family. Concerning the future role as a father/mother, boys were inclined to a role of a caring, loving, dutiful, and responsible family member who insures financial stability of the family, whereas girls favoured emotional saturation in the role of a mother ("playing with the kid", "showing love is important"). The question of what kind of a father (for the girls) or mother (for the boys) should their partner be, uncovered stereotypical views, especially in boys. Boys adhered to a more traditional gender differentiation of the parent roles ("father should be the money-maker, mother should take care of the children and household"), whereas girls adopted a more feministic-oriented stance aiming towards equality of both parents ("I don't see anything bad about a scenario where the woman works and the man takes care of the child").

\section{Conclusions}

Findings pointed to adolescent boys having a more problematic relationship with their fathers, and a significantly positive relationship with their mothers. Mothers not only represent an essential part of their lives, but also provide an emotional and mental support. Adolescent girls identified more with their mothers, highlighting mothers' ability to handle a vast number and diversity of family matters. The key factor in the positive rating of a mother was represented by safe emotional ties between the mother and daughter. However, in cases where these ties were missing, mother was perceived through the lenses of stereotypically female depictions, largely perpetuated by the mass media and agendas of certain political parties, even despite the increasingly present social campaigns highlighting equality between both genders.

\section{References}

Beauvoirová (de), S. (1968). Druhé pohlavie. Bratislava: Obzor.

Erikson, E.H. (1968). Identity, Youth and crisis. New York: W. W. Norton Company.

Hirsh, M. (1981). Mothers and daughters. Signs, 7(1), 200-222.

Krueger, R. A., \& Casey, M. A. (2000). Focus groups: A practical guide for applied research (4th ed). Thousand Oaks, CA: Sage Publications Inc.

Laible, D.J., Carlo, G., \& Roesch, S.C. (2004). Pathways to self-esteem in late adolescence: The role of parent and peer attachment, empathy, and social behaviours. Journal of adolescence, 27(6), 703-716.

Lindsey, L.L. (2016). Gender Roles: A sociological perspective (6 ${ }^{\text {th }}$ ed.). London, NY: Routledge.

Miller, T. (2011). Making Sense of Fatherhood: Gender, Caring, and Work. Cambridge, UK: Cambridge University.

Oláh, L.Sz., Kotowska, I.E., \& Richter, R. (2018). The New Roles of Men and Women and Implications for Families and Societies. In G. Doblhammer \& J. Gumà (Eds.), A Demographic Perspective on Gender, Family and Health in Europe (pp. 41- 64). Springer Open.

Poncet-Bonissol, Y. (2015). O matkách a dcerách. Praha: Portál.

Silverstein, L.B., Auerbach, C.F., \& Levant, R.F. (2002). Contemporary Fathers Reconstructing Masculinity: Clinical Implications of Gender Role Strain. Professional Psychology: Research and Practice 33(4), 361-369. 